\title{
Assessment of Informal Learning Program on Weather Phenomena: Its Perception and Necessity in Greece
}

\author{
Kyriaki Makri ${ }^{1}$, Elissavet Galanaki², Ioannis Koletsis ${ }^{3}$, Vassiliki Kotroni ${ }^{4}$, \\ Konstantinos Lagouvardos ${ }^{5}$
}

\section{ARTICLE INFO}

\section{Article History:}

Received 11.11.2019

Received in revised form

16.06.2020

Accepted

Available online 01.10.2020

\begin{abstract}
The inadequate approach of the weather phenomena, the associated atmospheric processes as well as their impacts at the Greek education led to the creation of the learning program "Peri Anemon \& Ydaton", by the meteorological unit of the National Observatory of Athens. The program, which is presented to Junior High School and High School students, is structured into five thematic sessions and covers eight learning goals, the implementation of which was assessed using a multipleresponse questionnaire. In general, the program "Peri Anemon \& Ydaton" is a vivid example for the efficiency of informal learning programs. Furthermore, it is the first attempt for the recording of the results as an assessment of an informal learning program on weather and climate in Greece. The learning program "Peri Anemon \& Ydaton" is implemented with the approval of the Educational Policy Institute of Greece, thus indicating its pedagogical adequacy.
\end{abstract}

C IJERE. All rights reserved

Keywords:

Informal learning, meteorology, assessment, perceptions.

\section{INTRODUCTION}

Natural hazards and their management are of great importance on the field of applied, technological, social and human science. During the past twenty years, natural disasters caused 1.3 million of deaths and affected another 4.4 billion of people worldwide (CRED \& UNISDR, 2018). About 91\% of the disasters were caused by rainfall, storms, droughts, heat waves and other severe weather phenomena. According to the United Nations International Disaster Reduction Strategy, the understanding of the hazards associated with natural disasters, as well as the increased awareness and preparedness of citizens can effectively contribute to the reduction of the impact on society (Sendai Framework 2015- 2030). Studies conducted with adults revealed that the lack of knowledge and awareness, combined with misconceptions, have a negative impact on preparedness and hazard management (Lindell and Witney, 2000). Education on natural disasters has been developing at international level, over the last two decades, since organized activities for raising awareness have an important contribution to the reduction of risks, as well as the increase of resilience to dangerous natural phenomena (e.g. Selby \& Kagawa, 2012). This knowledge could be provided, through education, which should include, apart from simple provision of new curriculum content in schools, informal education programmes, often conducted outside educational institutions (Bangaya \& Blum, 2010).

One of the most common methods of estimating the level of knowledge and awareness on natural hazards is to evaluate educational programs related to natural hazards and severe weather phenomena. The evaluation and assessment of educational programs is an emerging research topic that contributed to the evolution of these programs during the last 15 years. The evaluation results can be used to develop a program (needs assessment), to optimize the way of development of a program (formative evaluation), and to conclude about the need either to modify or to continue an existing program (summative evaluation). The summative evaluation contains the evaluation of a program after its completion (Ball, 2011). A program assessment is referring to a wide range of skills, and evaluators should originate from a variety of scientific disciplines: educational psychology, developmental psychology, psychometrics, sociology, statistics, anthropology, educational administration etc. Johnson et al. (2014) who have conducted an extensive research on the methodology for the evaluation of educational programs for students on natural disasters, pointed out that the evaluator should be involved in both the development and the presentation of the learning program. Ben-zvi-Azarf and Orion (2005) through their study, presented the alternative

\footnotetext{
${ }^{1}$ Corresponding e-mail: kikimakri@noa.gr, National Observatory of Athens, Institute of Environmental Research Greece \& Sustainable Development,orcid.org/0000-0002-8851-0376 2 orcid.org/0000-0001-9902-3488, National Observatory of Athens, Institute of Environmental Research Greece \& Sustainable Development 3 orcid.org/0000-0002-0033-1411, National Observatory of Athens, Institute of Environmental Research Greece \& Sustainable Development

${ }_{4}$ orcid.org/0000-0003-1248-5490, National Observatory of Athens, Institute of Environmental Research Greece \& Sustainable Development

5 orcid.org/0000-0001-8854-5862, National Observatory of Athens, Institute of Environmental Research Greece \& Sustainable Development
} 
frameworks used by students in order to understand the various aspects of the water cycle (Ben-zvi-Azarf and Orion, 2005).

In Greece, the general concepts of meteorology, weather and climate are found in the curriculum at Junior High Schools and High Schools but, concepts like severe weather phenomena and relevant protection measures are not included in the usual teaching interventions,. Nevertheless, there are a few informal educational programs dedicated to meteorology. A survey in Greek secondary school students (Liarakou et al. 2011) revealed that students who attended educational environmental programs, had increased their perception and ideas about severe weather phenomena. Another study in Greece (Spiropoulou et. al., 1999) focused on surveying students' concepts on weather and climate in Junior High School, also showed that the students who have participated in learning activities on weather phenomena, had the opportunity to improve their understanding on scientific processes and natural laws (Spiropoulou et. al., 1997). This survey was conducted in a sample of 18 students, who attended a project on weather and climate for six months, from December 1993 to May 1994, when the research on the field of the education on weather phenomena was at the early stages.

The paper is structured as follows: Section 2 is devoted to the presentation of the data and methods used, section 3 presents the results of the analysis while the last section focuses on the conclusions.

\section{Aim of the Study}

The meteo unit at the National Observatory of Athens, recognizing the need for science education on weather and climate, has built in 2016 a meteorological learning program for students entitled "Peri Anemon \& Ydaton". The structure and the context of this learning program aims to provide knowledge on severe weather phenomena, with emphasis on their impact on students and widely on the society. The content of the "Peri Anemon \& Ydaton" is in line with the curriculum of the Junior and High Schools and its structure is based on the constructive model of Driver \& Oldham (Driver, 1986). The main view of a constructivism model is that human learning is constructed with emphasis on the learners and not the teacher and, at the same time, the teaching approaches are promoting active learners' engagement. Furthermore, interactive teaching tools are used and communication and collaboration between students, rather than individual work, is enhanced, in order to facilitate the development of functional rather than inactive knowledge. Although different informal learning programs are implemented in Greece, this research is pioneer since "Peri Anemon \& Ydaton" includes a corresponding data assessment. The structure and the context of this learning program has an interdisciplinary as well as a holistic character. The interdisciplinary approach ensures the synthesis of knowledge, concepts and approaches from different sciences, natural and human, with the aim to unify the knowledge (Flogaiti, 2006).

In the frame of this study, we performed the assessment of the aforementioned learning program on weather phenomena with the aim to determine the students' relevant cognitive background and to record the improvement of perceptions of students through a learning program. In Greece, research on the conception and knowledge of Junior High Schools and High School students on weather phenomena has not been conducted over the past 20 years and this was the main motivation of this study.

\section{METHOD}

\section{The educational framework of the program}

The learning program "Peri Anemon \& Ydaton" aims to present and discuss the weather phenomena affecting the Mediterranean area, with emphasis on the severe weather phenomena. The main learning goals of the program are:
A. the creation of cyclonic and anticyclonic systems
B. the formation of the cold and warm fronts
C. the water cycle and the creation of clouds
D. the stability and the instability in the atmosphere
E. the cloud classification
F. the creation of thunderstorms
G. the creation of cloud-to-ground lightning strikes
$\mathrm{H}$. the formation of tornadoes. 
The dominant tool for teaching strategies is the didactic tool of the simulation (e.g. model), since the students can confirm or reject their conceptions about the development of the weather phenomena. Furthermore, the students can discover the characteristics of the weather phenomena, such as the creation of high intensity rainfall and thunderstorms, the formation of a tornado and the creation of lightning, while developing psychomotor skills. In the program, the students are separated in small groups in order to ensure members ' cooperation. In parallel, modern teaching tools (educational videos, interactive tablet applications, use of experiments) are implemented, aiming at the experiential approach of knowledge. For the above learning goals, Bloom's taxonomy was used, while the program targets eight overall goals (A, B, C, D, H, F, $\mathrm{G}, \mathrm{H}$ ). Bloom's taxonomy differentiates between cognitive skill levels in order to lead to deeper learning and transfer of knowledge and skills to a greater variety of contexts and tasks (Bloom, 1956).

The program is presented to Junior High School and High School students of Greece. The main vision of the program is that through proper education, students can adopt correct on the weather phenomena, while minimizing possible misconceptions and false conceptions. Consequently, the assessment of the learning program "Peri Anemon \& Ydaton" has been conducted in order to determine its stated goals, as well as to be used as an improvement tool for the learning program itself.

Students voluntarily attend the program following suggestions from school teachers, as a reinforcement action in the field of informal learning. Informal learning is the lifelong process by which a person acquires and accumulates knowledge, skills, attitudes and conceptions from everyday experiences and exposure to his or her environment.

\section{Description of the program "Peri Anemon \& Ydaton".}

The learning program "Peri Anemon \& Ydaton" consists of three parts. The first part consists of a conversation conducted with the students in order to assess their knowledge on weather phenomena. The second and main part of the program consists of the presentation of the program to the students using three different educational tools: theoretical development using videos (instead of static presentation slides), experiments and interactive application tools. Finally, the third part is the implementation of a quiz, consisting of 20 questions, as presented in Annex A, based on the knowledge acquisition of students. The program's structure of the second and main part of the program is summarized in Table 1.

Table 1 Structure of the program

Sessions of the program

\section{Theory}

Session I

(Weather Map \& Fronts)

Session II

(Water Cycle \& Stable conditions)

Session III

(Clouds' types)

Session IV

(Thunderstorms \& Measures on lightning protection)

(Tornadoes \& Waterspouts)

Session I: In the first session, the decoding of a weather chart as well as the creation and the movement of the warm and cold fronts are discussed. This session's goals are achieved using the appropriate theory and a demonstration experiment. During the theoretical part of the first session, the students learn about high and low pressure systems, their structure and how the air masses and the surface winds are driven. A weather map of a typical northern hemisphere winter day is used in order to decode the weather conditions. The meaning of the isobars contrasts with the contour lines of elevation, which are taught in the school curricula. At the final stage of this session, the warm and cold fronts and the associated weather are discussed. Also, an experiment within a tank is made showing how cold and warm air masses interact when they come in to contract with each other, creating a cold front. 
Session II: The objectives of this session are the comprehension of the main components of the water cycle, the role of sun, the formation of clouds and the various forms of precipitation (rain, snow or hail). A simple experimental setup is included in order to explain the different components of the water cycle and to observe the upward currents and the role of the size/weight of the hydrometeors before the formation of the rain. Finally the students are separated in small groups and based on the use of interactive applications on tablets they explore the formation of upward air motions due to thermal effects and the role of the thermodynamic characteristics of the atmosphere to the formation of clouds.

Session III: In this session, a cloud atlas of 10 basic cloud forms following the classification of Luke Howard (1803) is discussed. The theoretical part of this session is dedicated to the cloud nomenclature and discussion of the main characteristic of each cloud category, with particular emphasis on Cumulonimbus clouds which relate with intense weather phenomena such as thunderstorms, hail and tornadoes. Sometimes, depending on the weather conditions at the end of the program, the students are challenged to identify the clouds on the sky. Finally, with a simple experimental setup students are separated into groups and create a cloud inside a plastic bottle. The joy of this game is coupled with the knowledge of cloud creation in the atmosphere through adiabatic cooling. Depending on the school grade, cloud formation is explained through thermodynamic laws included in the school curriculum.

Session IV: This session is devoted to the explanation of the formation of the thunderstorms and the associated lightning activity. At the end of the theoretical approach, the main characteristics e.g. size, duration, frequency of occurrence, spatial and temporal occurrence) and the associated phenomena (e.g. hail, floods, high wind speed) of the thunderstorms of Greece are mentioned. This part of the session is complemented with an interactive application on tablets, which explains the atmosphere's necessary conditions and the role of atmosphere's instability for the formation of a thunderstorm. At the second part of this session, the formation of lightning and the associated protection measures are explained. The students are separated in small groups and three different experiments are performed in order to improve their knowledge on static electricity. Finally, a free discussion with the audience takes place about their experience with lightning activity.

Session V: The main objective of this session is the explanation of the formation of the tornadoes and waterspouts. Firstly, an analytical explanation of the necessary atmospheric conditions and the critical stages of the formation of a tornado are given. Subsequently, the main temporal and spatial characteristics of the tornadoes in Greece are given, along with the basic protection measures. This session is complemented with experimental devices that show the formation of tornadoes and waterspouts in order to improve the understanding on the vertical structure of a tornado and characteristics of the wind speed in a tornado. The use of the forementioned innovative educational tools aims to reinforce the transfer of knowledge (Papadopoulou \& Avdimiotis, 2020).

After completion of the second part of the learning program, with the aforementioned five sessions, the third part follows: a questionnaire consists of 20 questions is distributed to the students that are working in groups immediately after the completion of the second part in order to assess the obtained knowledge about the weather phenomena. Also, an imprinted questionnaire is distributed to the teachers in order to obtain their assessment of the learning program as well as their impressions and suggestions.

The questionnaire was developed with the ultimate goal, to draw conclusions and make proposals for the design of appropriate interventions within the framework of curricula and Environmental Education. Indeed, students' concepts and opinions on environmental issues are important since they are useful for the design and evaluation of teaching material of educational contexts, environmental education programs and science lessons (Koulaidis \& Christidou, 1999). A similar methodological approach was used in a recent study (Papakitsos, et.al 2019) who evaluated high-school students' opinions on space professions.

\section{Methodology used for the program assessment}

In order to design and implement the evaluation of learning programs, the following main phases are followed: data collection strategy, data analysis and conclusions production. The quantitative questionnaire is the most common data collection method, and is based on multiple choice questions (Johnson et al, 2014). The evaluator, ideally, raises, at the first stage, the questions of data analysis. The data collection and processing serves the purpose of covering the above queries. 
The methodology as well as the associated tools which are used to evaluate a learning program is critical. Gronlund (1990) has defined the term evaluation as "a systematic process of collecting, analyzing and interpreting information to determine the extent to which students achieve instructional objectives". In the evaluation process, the first step is to determine the objective of evaluation and to quantify the achievement of the educational goals.

The use of the term "evaluation" for a learning program means that certain conditions are met (Ball, 2011):

i. The resemblance between the program goals as set in theoretical basis and the achieved goals as the program is implemented.

ii. The resulting benefits and positive effects from the cooperation of developers and evaluators for the explication program goals.

iii. The extent of conducted research before the specification of the program goals.

iv. The extent of consciousness of the evaluator about the intended and unintended outcome of the program referred to the program goals.

In this study from the above list of conditions, the first two are partially fulfilled, while the last two are not met.

The terms assessment and evaluation are difficult to be distinguished at the field of the research in education. The basic principles of assessment and evaluation, are identical, as well as the purpose for which they are implemented. Assessment is commonly defined as the systematic process to measure skills, beliefs, knowledge and attitudes by the use of data. The scope of the assessment is the evaluation and monitoring of the learning progress, aiming at the improvement of learning results on a continuous basis (Allivna \& Mundilarto, 2019). On the contrary, the term evaluation focuses on grades without taking into account the mastery level and the course content. At the present study, the use of the term assessment is chosen, since the "Peri Anemon \& Ydaton" is an informal learning program where its purpose is not the students' rating.

The present study is the first attempt to assess the degree of cognitive understanding of students' on weather phenomena in Greece. The research methodology is based on the qualitative and quantitative assessment of the replies on the quiz questions, namely the analysis of the percentages of the correct answers while content analysis and document analysis were used for analyzing the collected data. Qualitative data analysis is complicated by the volume of data generated, and the challenge for the researcher is to conduct an in-depth analysis, and yet present the findings in a concise and logical way (Clifford, 1997). Quantitative research tools were also used in order to obtain a general picture of the students' knowledge and conceptions (Orion, 2007).

The data are derived from the questionnaire distributed during the final phase of the program. Indeed the questionnaire is a closed-form questionnaire consisting of 20 statements about causes, impacts and protection measures about the weather phenomena. The questionnaire was developed by educators during the development phase of the learning program and has not changed during the assessment process.

The implemented method of this study follows the content analysis of the data derived from the closedform questionnaire as Fraenkel \& Wallen (2009) suggest. Content analysis is a method that enables researchers to study human behavior in an indirect way, through an analysis of their written responses (Fraenkel \& Wallen, 2009).The content analysis is a method that has wide applicability in educational research.

The same methodology has been applied in relevant surveys that seek to draw qualitative conclusions about students' attitudes and opinions (Ben-zvi-Assarf and Orion, 2005; Cepni, 2014). Indeed, Ben-zvi-Assarf and Orion (2005) used 4 different data tools (questionnaires, interviews, sketches and texts) in order to understand the various aspects of the water cycle. This study revealed the difficulties in understanding the systemic-dynamic nature of the water cycle. It is observed that most of the students could not make a connection between the atmospheric water sub-cycle and the geospheric underground water sub-cycle, as well as the majority of students had difficulties to perceive the transformation of matter (water) in the earth reservoirs, and to synthesize components into a coherent system. 
In addition, the interpretation of the results was based on the content analysis method because of the random and unbalanced sample. In the opposite case, when the aim is to compare, correlate and generalize the results (Stamou et.al. 2007 \& Summer et.al, 2000), a quantitative methodology can be selected (Liarakou et al., 2011).

A corresponding to the presented study methodological approach was used in a relevant study (Papakitsos, et.al 2019) concerning the concepts and perceptions of high-school students on space professions. In this study, a questionnaire for determining the opinions of senior high-school students had been designed and used for conducting a limited preliminary survey.

At this point it is worth mentioning that the learning program "Peri Anemon \& Ydaton " is implemented with the approval of the Educational Policy Institute of Greece, thus indicating its pedagogical adequacy. (Ministry of Education \& Religious Affairs).

\section{Data Collection}

The data for this assessment were collected during the academic year 2018 -2019. Students whose classes attended the learning program "Peri Anemon \& Ydaton", were asked to complete voluntarily a multiple-choice questionnaire with 20 questions. The 20 questions strongly related to the eight (8) learning objectives presented in section 2.1 as follows: A: Q1, 2, B: Q3, 4, 5, C: Q7, 8, 18. D: Q6, E: Q9, 10, F: Q13, 14, 15, 16, 20, G: Q12, 19, H: Q11, 17. Every question is an assessment criterion relevant to the learning goal.

The questionnaire is distributed as a software application and students are informed of their score at the completion of the questions. The study group is random and consists of 600 questionnaires, filled in by Junior High Schools' and High Schools' students originating from various regions of Greece. Students who attended the training program are $12-16$ years old. Other data concerning the features of the sample, such as gender, age, ethnicity etc, are not collected.

\section{FINDINGS}

The analysis of the 600 questionnaires (part 3 of the program) is presented at the following Tables and Figures. The percentage of correct answers that correlated to the sessions (I-V) and the learning goals (A-H) are also presented. Table 2 presents the list of questions with the relevant session and learning goal along with the corresponding percentage of correct answers, while Table 3 presents the average percentages of correct answers per learning goal.

The highest percentages (92\%) of correct answers appear for Q3, which is related to the learning goal B (the formation of cold and warm fronts). Goal B shows also the highest cumulative percentage $(82 \%)$ with all related questions $(\mathrm{Q} 3,4,5)$ where it presents scores greater than $75 \%$. The second best result $(77 \%)$ are those of learning goal $\mathrm{G}$, which refers to the creation of cloud-to-ground lightning strikes where the corresponding percentages of correct answers to questions Q12, Q19 are greater than $73 \%$. These results may relate with the fact that students are more familiar with terms and concepts associated to cold and warm fronts, as a result of weather reports presented in the media and with lightning through personal experiences.

The analysis of the answers of the Junior High School and High School students, showed that for 10 out of the 20 questions the percentages of correct answers were higher than $70 \%$, while for 4 the percentages are equal or below $50 \%$. Indeed, the cognitive conceptions of Q2, Q9, Q15 and Q20 cannot be considered as successful, taking into consideration their quite low percentage of correct answers (below 50\%). The two lowest percentages are related with learning goal $\mathrm{F}$ (creation of thunderstorms). The lowest cumulative percentages per learning goal $\sim 60 \%$ are also obtained for goal $\mathrm{F}$.

At this stage it would be instructive to investigate if there is a difference in the cognitive perceptions between the two stages of education, namely Junior High School and High School. Table 3 presents the percentage of the correct answers per educational stage. It should be noted that the percentage of High School students is relatively low (14\% of the sample) and this fact should be taken into account when analyzing the percentages provided in Table 3. The comparison of the correct answers between the Junior High School and High School students reveals that the percentages of the correct answers of the High School students are higher, approximately about 10\%, averagely, as shown in Figure 1. Low deviation between the correct answers of Junior High School and High School students are observed concerning Learning goals A 
and E, medium deviation for Learning goals B, F and G, while high deviation is found for Learning goals C, $\mathrm{D}$ and $\mathrm{H}$, since High School students have been taught relevant topics to a greater extent.

Table 2. List of Questions (per session and learning goal) and respective percentage of correct answers

\begin{tabular}{|c|c|c|c|}
\hline Questions & Session & Correct answers & Learning goal \\
\hline Q1 & I & $81 \%$ & $A$ \\
\hline Q2 & 1 & $47 \%$ & $A$ \\
\hline Q3 & I & $93 \%$ & B \\
\hline Q4 & I & $78 \%$ & B \\
\hline Q5 & 1 & $76 \%$ & B \\
\hline Q6 & II & $64 \%$ & $D$ \\
\hline Q7 & II & $57 \%$ & $\mathrm{C}$ \\
\hline Q8 & II & $82 \%$ & $\mathrm{C}$ \\
\hline Q9 & III & $47 \%$ & $E$ \\
\hline Q10 & III & $83 \%$ & $E$ \\
\hline Q11 & V & $77 \%$ & $\mathrm{H}$ \\
\hline Q12 & IV & $81 \%$ & G \\
\hline Q13 & IV & $87 \%$ & $\mathrm{~F}$ \\
\hline Q14 & IV & $68 \%$ & $\mathrm{~F}$ \\
\hline Q15 & III & $47 \%$ & $\mathrm{~F}$ \\
\hline Q16 & IV & $60 \%$ & $\mathrm{~F}$ \\
\hline Q17 & V & $68 \%$ & $\mathrm{H}$ \\
\hline Q18 & II & $65 \%$ & $\mathrm{C}$ \\
\hline Q19 & IV & $76 \%$ & G \\
\hline Q20 & IV & $41 \%$ & $\mathrm{~F}$ \\
\hline
\end{tabular}

Session I (Weather Map \& Fronts) - Session II (Water Cycle \& Stable conditions) - Session III (Clouds' types) Session IV (Thunderstorms \& Measures on lightning protection) - Session $\boldsymbol{V}$ (Tornadoes and Waterspouts) A: creation of cyclonic and anticyclonic systems, B: formation of the cold and warm fronts, $\boldsymbol{C}$ : water cycle and the creation of clouds, D: stable and the instable in the atmosphere, E: cloud classification, F: creation of thunderstorms, $\boldsymbol{G}$ : creation of cloud-to-ground lightning strikes, $\boldsymbol{H}$ : formation of tornadoes. 
Table 3. Average percentages of correct answers per learning goal, in correlation to educational stages

\begin{tabular}{|c|c|c|c|c|c|c|c|c|c|c|}
\hline \multirow[b]{2}{*}{$\%$ Average of correct answers } & \multicolumn{10}{|c|}{ Learning goal } \\
\hline & \multicolumn{2}{|c|}{ A } & B & C & & 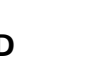 & E & \multicolumn{2}{|r|}{ G } & H \\
\hline Total sample of students & $64 \%$ & $82 \%$ & & $68 \%$ & $64 \%$ & $65 \%$ & $61 \%$ & $79 \%$ & $72 \%$ & \\
\hline High School Students & $67 \%$ & $90 \%$ & & $83 \%$ & $76 \%$ & $70 \%$ & $69 \%$ & $87 \%$ & $86 \%$ & \\
\hline Junior High School Students & $64 \%$ & $81 \%$ & & $65 \%$ & $62 \%$ & $65 \%$ & $59 \%$ & $78 \%$ & $70 \%$ & \\
\hline $\begin{array}{r}\text { A: creation of cyclonic and ant } \\
\text { creation of clouds, D: stable and the } \\
\text { creation of } c\end{array}$ & $\begin{array}{l}\text { clonic } \\
\text { stable } \\
\text { d-to-c }\end{array}$ & $\begin{array}{l}\text { tems, } \\
\text { he atm } \\
\text { ind ligh }\end{array}$ & in & $\begin{array}{l}\text { E: clo } \\
\text { ikes, } \boldsymbol{H}\end{array}$ & $\begin{array}{l}\text { e cold a } \\
\text { classific } \\
\text { ormatio }\end{array}$ & $\begin{array}{l}\text { nd warm } \\
\text { cation, } F \text { : } \\
\text { n of torn }\end{array}$ & $\begin{array}{l}\text { fronts, } \\
\text { creation } \\
\text { adoes. }\end{array}$ & $\begin{array}{l}\text { water cyc } \\
\text { f thunder }\end{array}$ & $\begin{array}{l}\text { and the } \\
\text { orms, } \mathbf{G} \text { : }\end{array}$ & \\
\hline
\end{tabular}

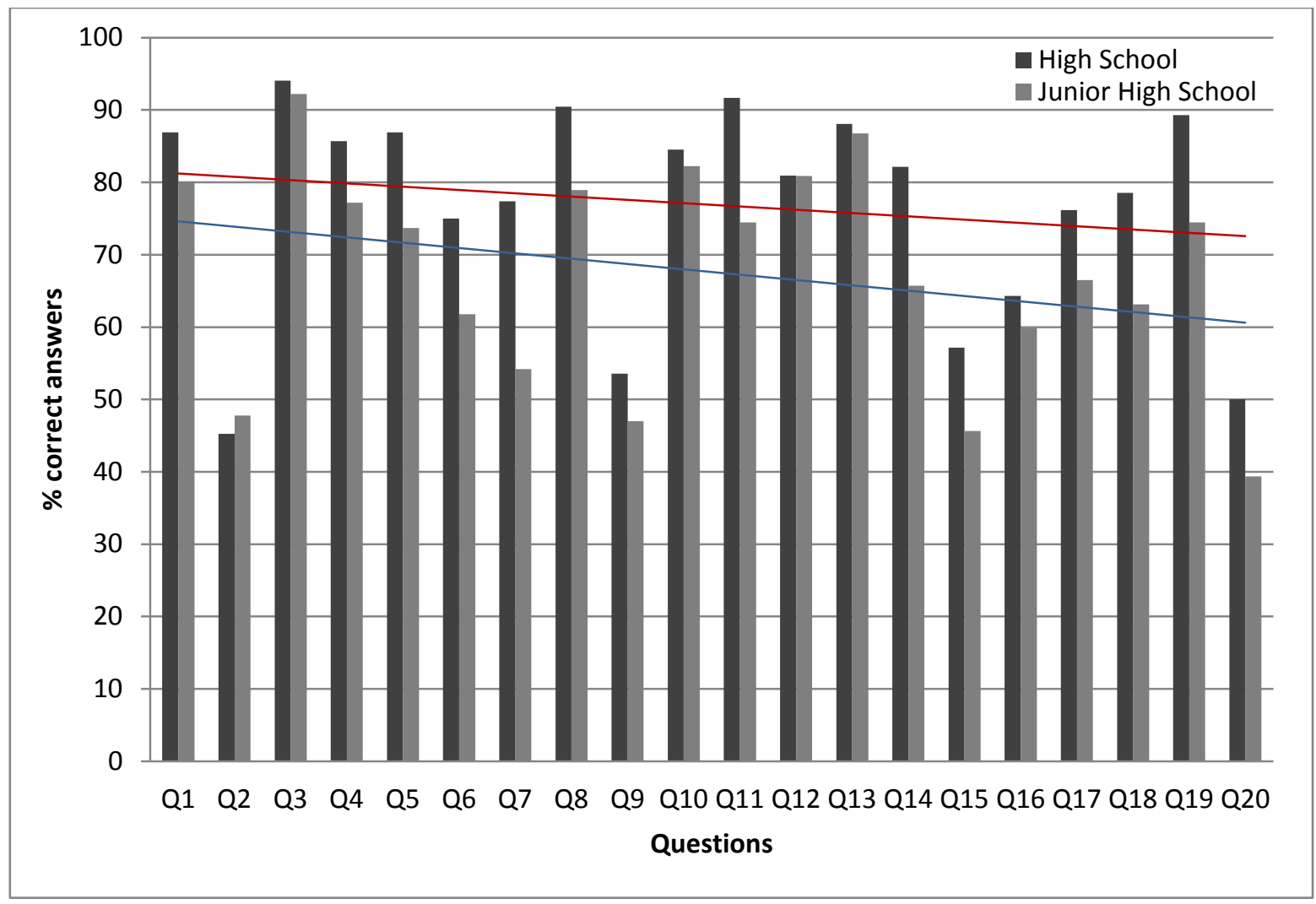

Figure 1. Percentage of correct answers for Q1-Q20 for the Junior High School and High School students

Figure 1 presents the percentage of the correct answers of Q1- Q20 per educational stage. The percentage of correct answers given by High School students is higher than that of Junior High Scholl for all answers, except Q2. The highest deviation ( 23\%) concerns Q7 on the source of energy on the water cycle. Furthermore, high deviation is also observed at Q11 $(\sim 17 \%)$ about the formation of tornadoes, as well as at Q14 ( 16\%) about the creation of thunderstorms. On the contrary, the percentage of correct answers deviation is small $(0 \%-4 \%)$ for Q16, Q19, Q3, Q13, Q12, Q2, which are relevant to the classification and creation of clouds, as well as the weather maps \& fronts. Although the relative sample of High School students is small a tentative conclusion drawn from the above is that for the questions that relate with the educational level (such as knowledge on sources of energy) the percentage of correct answers is higher for High School students, while for the questions that relate with observingness (creation of clouds) there is almost no difference in the cognitive conceptions between the two categories.

For the assessment of the learning program per session in relation to the teaching tools (theory, experiment, interactive application) used in each session, the correct answers were grouped accordingly in 
Table 4. The results presented in this table shows that Sessions I (Weather Map \& Fronts) and V (Tornadoes and Waterspouts) with percentages of correct answers $75 \%$ and $72 \%$ respectively, contain knowledge which can be better perceived by the students. These high results can be attributed to the fact that the curriculum includes some information on weather maps, the water cycle, resulting in the students' familiarization on these terms (Sessions I \& V). On the other hand, students could hardly name the Cloud types (Session III) as the low percentages of correct answers reveals. The lack of familiarization with Clouds' types can also be attributed to the fact that they are not included in the Greek curriculum. This conclusion is often observed in relevant studies, such as the one conducted in Israel (Ben-zvi-Assarf, and Orion, 2005), where students were able to understand various hydro-bio-geological processes and were aware of the atmospheric part of the water cycle (also included in the curriculum in Israel). On the other hand, the observed high score of correct answers for Session V could be attributed to the students' increased interest on impressive weather phenomena such as tornadoes.

Table 4. Responses of each module per session and learning goal

\begin{tabular}{lcccccc}
\hline $\begin{array}{l}\text { Sessions of the } \\
\text { program }\end{array}$ & $\begin{array}{c}\text { Numb } \\
\text { er of } \\
\text { questions }\end{array}$ & $\begin{array}{c}\text { Learnin } \\
\text { g Goals }\end{array}$ & $\begin{array}{c}\text { Average of } \\
\text { Correct } \\
\text { Answers }\end{array}$ & $\begin{array}{c}\text { The } \\
\text { ory }\end{array}$ & $\begin{array}{c}\text { Experi } \\
\text { ment }\end{array}$ & $\begin{array}{c}\text { Intera } \\
\text { ctive } \\
\text { Application }\end{array}$ \\
\hline Session I & 5 & A, B & $75 \%$ & $V$ & $V$ & $x$ \\
Session II & 4 & C, D & $67 \%$ & $V$ & $V$ & $V$ \\
Session III & 3 & E, F & $59 \%$ & $V$ & $V$ & $x$ \\
Session IV & 6 & F, G & $69 \%$ & $V$ & $V$ & $V$ \\
Session V & 2 & H & $72 \%$ & $V$ & $V$ & $x$ \\
\hline
\end{tabular}

The matching of each learning goal with the structure of the program (Sessions) is presented at Table 5 in descending order. As it is observed, Sessions I, IV and V fulfill the corresponding learning goals of the program (learning goals $\mathrm{B}, \mathrm{G}$ and $\mathrm{H}$, respectively), owning percentage of correct answers from $72 \%-82 \%$. The need of enhancement of the Sessions III, II and I for the achievement of the learning goals F, D and A, respectively, is proven by the lower percentage of correct answers (61-64\%). Approaching the relationship between students' conceptions and program structure (Table 5), the sessions Weather Map \& Fronts (I) and Measures on lightning protection (V) seems to be implemented with high competence. The sessions Tornadoes and Waterspouts Thunderstorms (IV) and Water Cycle \& Stable conditions (II) are also implemented with high competence and satisfactory results. On the contrary, the session about Clouds' types needs reinforcement, as students ' conception is moderate.

Moreover, Table 5 shows that the absence of interactive applications is not reflected in the obtained low percentage of correct answers. Indeed, despite the fact that sessions I and V do not include interactive applications, the obtained percentages of correct answers are the highest. To explain students' moderate conception of cloud classification, one should look at their knowledge of formal education. At the list of Greek High School textbooks (http://ebooks.edu.gr/), it is observed that cloud classification is not a topic in Science or Geoscience. At the same time, Greek students approach through formal education the topics of Water Cycle, Weather Maps and general climate issues, which is a possible explanation for the high conception rates for these areas. For the same reason, the topic of thunderstorms is familiar to students, as it is often approached as an example in the field of electricity. Moreover, tornadoes and waterspouts, are not part of the Greek curriculum, but they are striking natural phenomena that are probably best reflected in the students ' conception. 
Table 5. Descending rank order of learning goals per Session

\begin{tabular}{|c|c|c|c|c|c|c|c|c|}
\hline $\begin{array}{c}\text { Learning } \\
\text { Goals }\end{array}$ & B & $\mathbf{G}$ & $\mathrm{H}$ & C & $\bar{E}$ & A & D & $F$ \\
\hline Session & 1 & IV & V & II & III & 1 & II & III \\
\hline
\end{tabular}

The analysis of the above correct answers obtained by the 600 students' questionnaires shows that they have a correct view of the definitions of meteorological phenomena. At the same time, it is evident that students have acquired a deep knowledge about weather phenomena, as they have experienced and observed through their daily lives. On the other hand, high rates of incorrect answers (> 50\%) are obtained for questions that relate to atmospheric circulation, since they do not have the relevant knowledge nor the experiential familiarization.

Figure 2 presents the relative frequency of correct answers. For this analysis, the assumption that the $5 / 10$ grade (or $50 \%$ ) is considered as successful, was adopted. As it is obvious from Figure 2, the majority of students have a score from $50 \%-85 \%$, proving that the learning program achieves its educational goals, at a satisfactory level. The percentage of correct answers in the range of $50-70 \%$, ranged from $8-10 \%$ of the students. The corresponding percentage of correct answers from $75 \%-85 \%$ was $10-12 \%$ of the students, showing that this is the dominant range of students with correct answers. On the contrary, the percentage of correct answers which range from 30 to $45 \%$ and from $90 \%$ to $100 \%$ was less than $6 \%$ of the students. The percentage of students who provided correct answers follows a (left skewed) Gaussian distribution (Fig.2), revealing that the sample is representative, and that the questionnaire was built according to the learning program and the average cognitive level.

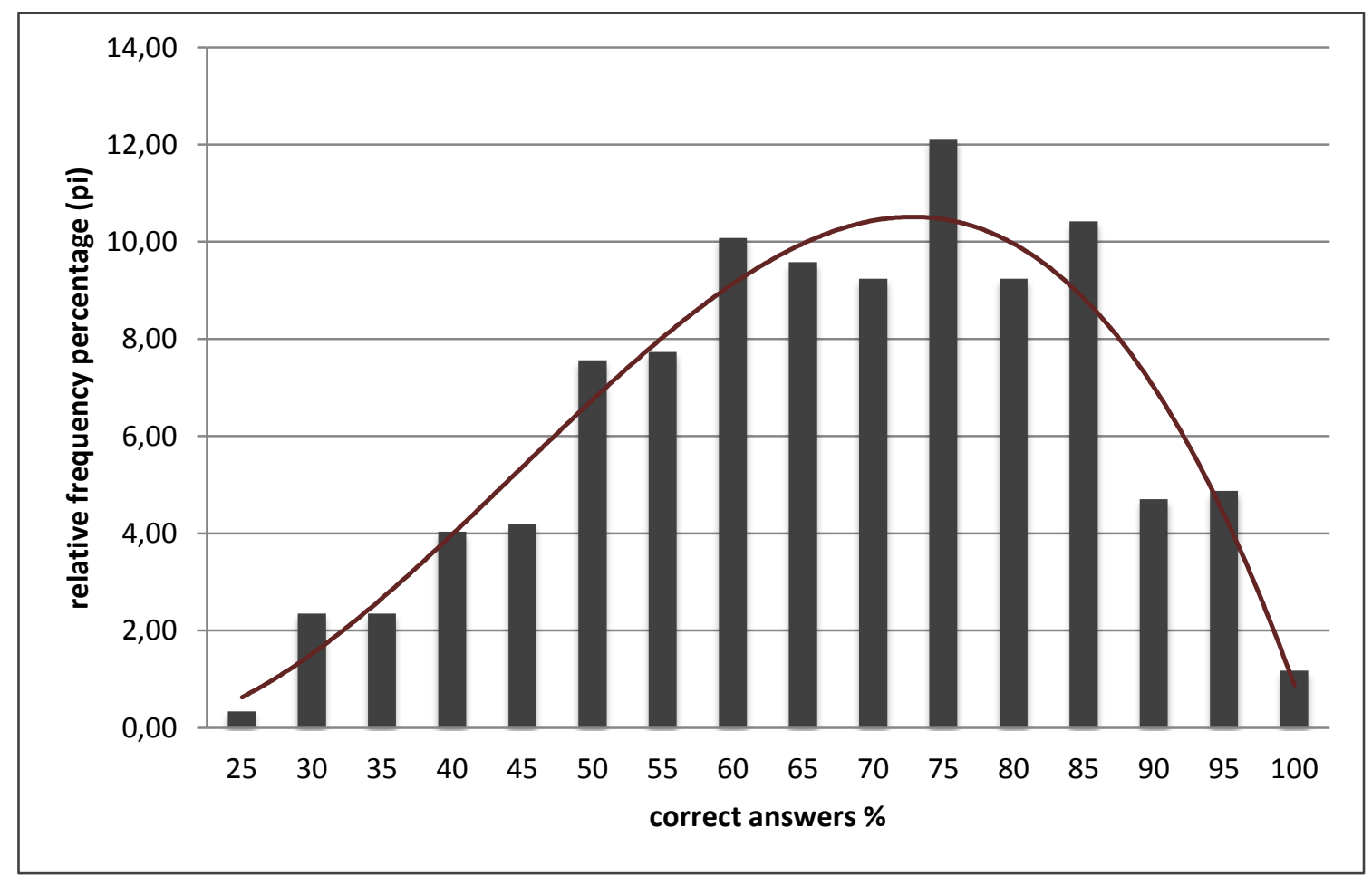

Figure 2. Relative frequency of correct answers (pi)

Figure 3 shows that the cumulative percentage of correct answers with a score lower than $35 \%$ is almost $5 \%$. It is noteworthy that the predominant range of students with correct answers falls in the range 
$50-85 \%$. The obtained results prove that the overwhelming majority of students had successfully answered the questions, consistently to a normal (Gauss) distribution (Spiegel, 2000). Based on the above results, it is also evident that the learning program 'Peri Anemon \& Ydaton' is achieving at a great extent its learning goals.

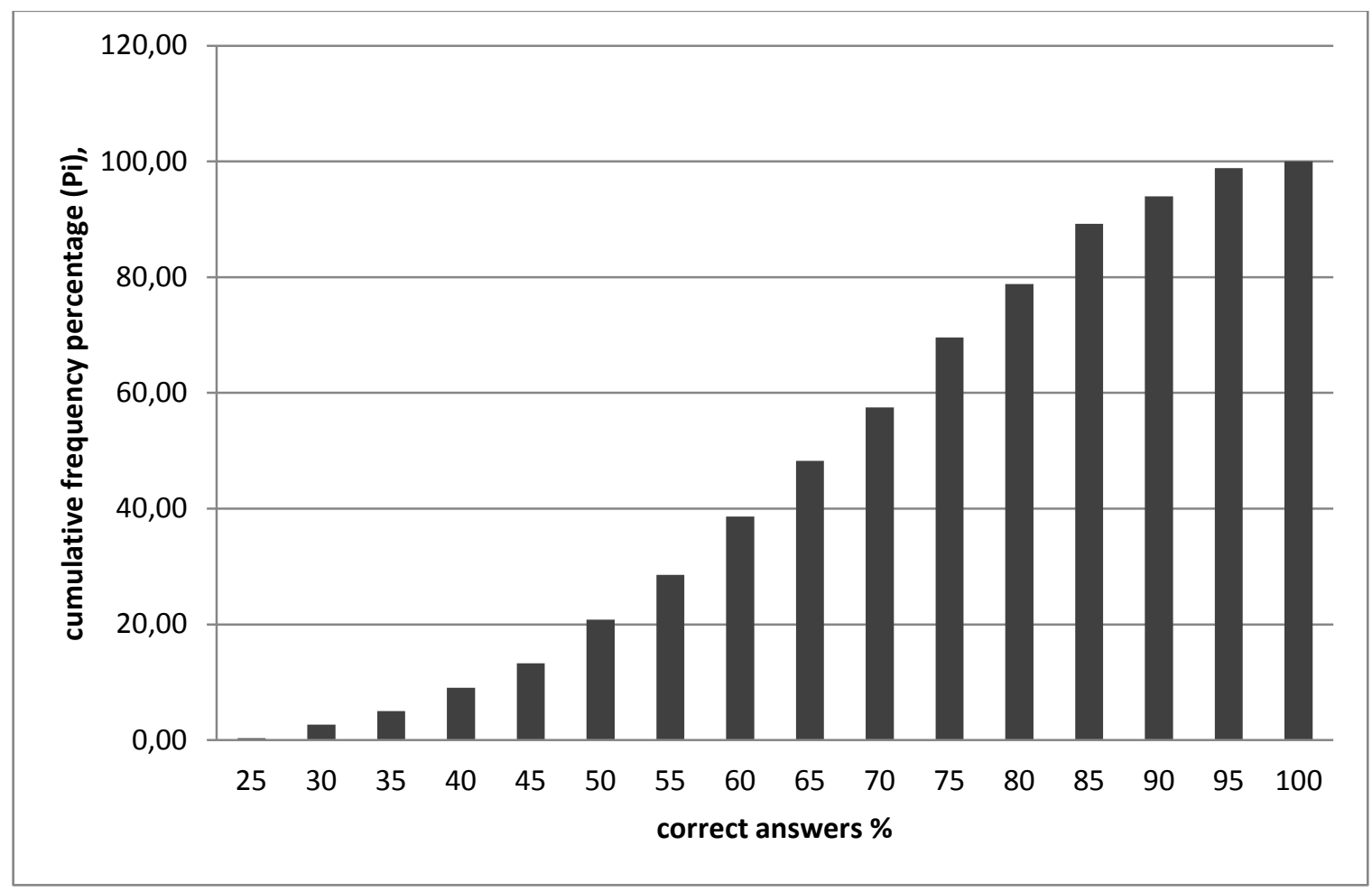

Figure 3. Cumulative frequency of correct answers (Pi)

\section{Teachers' assessment}

The students attend the program "Peri Anemon \& Ydaton" by the decision and encouragement of their teachers. Therefore, the reporting of the teachers' views was considered to be an important indicator on the success of the program in meeting their educational expectations, ans important way to obtain suggestions for the improvement pf future implementation of the program.

Apart from the assessment of the students' achieved cognitive level on weather phenomena, the teachers' opinion about the learning program has been also analyzed and the results are presented in Table 6. For this analysis, 60 questionnaires (Annex B) were analyzed. The educators asked the teachers for their opinion and in particular asked about school competence and relevance with the curriculum. The teachers' questionnaire was completed anonymously by the aforementioned 60 teachers, both in paper form as well as in online form, without having collected other data concerning the features of the teachers' sample, such as gender, age, ethnicity etc.

Teachers' opinion concerning the school competence, the relevance with the curriculum and the educators performance appear to be positive at a very high level (Table 6). The assessment by the teachers, which is very positive, is an indicator of the necessity for the continuation of the program and its further development. At the same time, it also highlights the need to reinforce the lack of knowledge about weather phenomena in the curricula. 
Table 6. Teachers' opinion concerning the program on school competence and relevance referred to curriculum.

\begin{tabular}{|c|c|c|c|c|c|}
\hline Questions & Absolutely & Much & Quite & $\begin{array}{l}\text { Not so } \\
\text { much }\end{array}$ & $\begin{array}{l}\text { Refused } \\
\text { to } \\
\text { answer }\end{array}$ \\
\hline $\begin{array}{l}\text { Does the presented cognitive content } \\
\text { relate to the subject matter of the curriculum? }\end{array}$ & $38 \%$ & $50 \%$ & $10 \%$ & $0 \%$ & $2 \%$ \\
\hline $\begin{array}{l}\text { How satisfactory is the organization and } \\
\text { structure of the learning program? }\end{array}$ & $75 \%$ & $22 \%$ & $3 \%$ & $0 \%$ & $0 \%$ \\
\hline $\begin{array}{l}\text { How do you evaluate the impact of the } \\
\text { program on the students' knowledge on } \\
\text { weather phenomena? }\end{array}$ & $75 \%$ & $20 \%$ & $5 \%$ & $0 \%$ & $0 \%$ \\
\hline $\begin{array}{l}\text { Overall, are you satisfied by the } \\
\text { educators? }\end{array}$ & $90 \%$ & $10 \%$ & $0 \%$ & $0 \%$ & $0 \%$ \\
\hline
\end{tabular}




\section{RESULT, DISCUSSION, AND SUGGESTIONS}

In the frame of this work, the learning program "Peri Anemon \& Ydaton" is evaluated based on the analysis of 600 questionnaires filled in by students and 60 questionnaires filled in by their teachers. Other data concerning the features of the sample, such as gender, age, ethnicity etc, are not collected. The implemented method of this study follows the content analysis of the data derived from a closed-form questionnaire. The primary goal is to determine the obtained cognitive background on weather phenomena from the Junior High School and High School students in Greece. It was found that the program achieves to a large extent its learning goals. In particular, students have a greater understanding on the formation of the cold and warm fronts, the creation of cloud-to-ground lightning strikes and the formation of tornadoes (learning Goals B, G, H). The students ' understanding of water cycle \& cloud classification and creation of cyclonic and anticyclonic systems, is considered satisfactory (learning Goals C, E, A). On the contrary, students ' understanding on stability and instability in the atmosphere and the creation of thunderstorms, is comparatively low (learning Goals D, F). Moreover, the teachers' opinion was recorded as strongly positive on the learning program, and more particularly on the relevance with the curriculum, the school competence and the educators.

The results revealed that two sessions are implemented with high competence, two other sessions are also implemented with high competence and satisfactory results, while one session needs reinforcement. In general, interpretations of the relationship between conception and cognitive content in textbooks are the subject of further ongoing research, since data analysis and assessment reveal students' conception on severe weather phenomena, enhancing teaching strategies in the Greek formal education.

It is also remarkable the high level of students' critical thinking skills during the attendance of the present learning program. On the contrary, recent research on the level of students' critical thinking skills in Science inside a classroom is of low order, due to the fact that science classrooms are still strongly teacher directed (Oliveira \& Rodrigues, 2004, Asysyifa et.al., 2019).

Results further suggested that the learning program "Peri Anemon \& Ydaton" provided meaningful learning experiences to Junior High School and High School students. Moreover, the need for enhancement of the Session concerning the learning goals on the stability and the instability in the atmosphere as well as the cloud classification has been noticed. These results will be a useful tool for the successful continuation and improvement of the program.

For the further improvement of this study, it is advised to focus on the special characteristics of the students, (e.g. age, geographical region, social background) in order to obtain a more detailed estimation of the parameters that influence the students' perception about weather phenomena.

It is pointed out that the sample, at the present and at future time, is those students and teachers that voluntarily attend the learning program "Peri Anemon \& Ydaton". In any case, the only precondition is the age of the students which should be 13-18 years old. 
Acknowledgements: The first author is financed by the project "Reinforcement of Postdoctoral Researchers - 2nd Cycle" (MIS-5033021), implemented by the State Scholarships Foundation (IKY). This project is co-financed by Greece and the European Union (European Social Fund- ESF) through the Operational Programme «Human Resources Development, Education and Lifelong Learning».

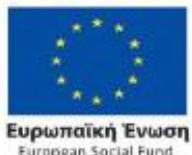




\section{REFERENCES}

Allivna \& Mundilarto (2019). Developing instrument assessment of student's process skills in physics learning based on local wisdom. International Journal of Educational Research Review, 4(4),489-495.

Asysyifa,D.S., Jumadi, Wilujeng,I. \& Kuswanto,H. (2019). Analysis of students critical thinking skills using partial credit models $(\mathrm{Pcm})$ in physics learning. International Journal of Educational Research Review,4(2), 245-253. DOI https://doi.org/10.24331/ijere.518068.

Ball, S. (2011) Evaluating Educational Programs, ETS RED Scientific and Policy Contributions Series. ETS Research Report No. RR-11-15.

Bangaya, C., Blum N. (2010). Education responses to climate change and quality: Two parts of the same agenda? International Journal of Educational Development,30 (4), 359-368.

Ben-zvi-Assarf, O., and N. Orion (2005) A study of junior high students' perceptions of the water cycle. Journal of Geoscience Education, DOI: 10.5408/1089-9995-53.4.366.

Bloom, B. S. (1956). Taxonomy of educational objectives: the classification of educational goals. New York NY: Longmans, Green.

Cepni, O. (2014). The concept of weather event: A qualitativen perspective from students. DOI: 10.1080/09720073.2014.11891552.

Clifford, C. (1997). Qualitative research methodology in nursing and healthcare. Open Learning Foundation/Churchill Livingstone, Edinburgh

CRED \& UNISDR Report, (2018). Economic losses, poverty \& disasters 1998-2017. https://www.emdat.be/publications.

Davis, E. (2010). Untangling dimensions of middle school students' beliefs about scientific knowledge and science learning. DOI https://doi.org/10.1080/09500690210145765.

Driver R. \& Oldham V., (1986). A constructivist approach to curriculum development in science. Studies in Science Education, 18, 105-122.

Fraenkel, R. J. \& Wallen E. N. (2009). How to design and evaluate research in education. McGraw-Hill, ISBN 9780-07-352596-9.

Johnson, V., Ronan R., Johnson, M., Peace, R., (2014). Evaluations of disaster education programs for children: A methodological review. International Journal of Disaster Risk Reduction, 9, 107.

Kapıkıran,N.A. \& Gündoğan,A. (2018). Assessment for c hildren's values: Picture -based value survey for children adaptation study. International Journal of Educational Research Review,3(2),9-21.DOI https://doi.org/10.24331/ijere.391804.

Koulaidis, V., \& Christidou V. (1999). Models of students thinking concerning the greenhouse effect and teaching implications. Science Education, 83(5), 559-576.

Liarakou, G., Athanasiadis, I., Gavrilakis, C., (2011). What Greek secondary school students believe about climate change? International Journal of Environmental \& Science Education,6(1), 79-98.

Lindell, K. \& Whitney J., (2000). Correlates of household seismic hazard adjustment adoption. Risk Analysis, $20,13-25$

Luke Howard (2010). 1865: Essay on the modification of clouds. Kessinger Publishing, LLC.

Michail, S., Stamou, A.G., \& Stamou, G.P. (2007). Greek primary school teachers" understanding of current environmental issues: An exploration of their environmental knowledge and images of nature. Science Education, 91(2), 244-259.

Papadopoulou,E. \& Avdimiotis,S. (2020). Educational innovation affects leadership and interpersonal relations in an experimental school in Northern Greece. International Journal of Educational Research Review,5(1),61-69. 
Papakitsos, C. E., Mavrakis A., Karakiozis K., Vamvakeros X. (2019). Determining the Opinions of pupils on space professions: A local case study (Greece). International Educational Research, https://doi.org/10.30560/ier.v2n1p14.

Rye, J.A., Rubba P.A., \& Wiesenmayer R.L. (1997). An investigation of middle school students' alternative conceptions of global warming. International Journal of Science Education, 19(5), 527-551.

Selby, D. \& Kagawa F., (2012). Disaster risk reduction in school curricula: Case studies from thirty countries. ISBN 978-92-3-001087-4.

Shepardson, P. D., Niyogi, D., Cho,i S., Charusombat, U. (2011). Students' conceptions about the greenhouse effect, global warming, and climate change. Climatic Change, 104, 481-507. DOI 10.1007/s10584-0099786-9.

Spiropoulou D., Kostopoulos D., \& Iacobides C.P. (1999). Greek Pupils' Alternative conceptions about weather and climate. School Science Review, 81(294), pp.55-59, London.

Spiropoulou, D., Kostopoulos D. \& Jakovides C.P. (1997). Weather phenomena in the Greek national curriculum: an experiment in teaching meteorology. Weather, 52, 282-286 14.

Summers, M., Kruger C., Childs A., \& Mant J. (2000). Primary school teachers" understanding of environmental issues: An interview study. Environmental Education Research, 6(4), 293-312.

Oliveira; M. and Rodrigues, A. (2004). Portfolio as a strategy to interrelate research in education and physics teachers practices. In M. Michelini (Ed.), Quality development in teacher education and training: Second International GIREP Seminar 2003 selected contributions, Forum, Udine, Italy. 


\section{Annex A: Questionnaire for students.}

Q1. At a low barometric pressure system, in the Northern Hemisphere, the wind on the earth's surface is rotating:
a) Clockwise
b) Anticlockwise
c) Irregular direction, depending on its geographical location

Q2. At a low barometric pressure system in the mean sea level pressure, the pressure:
a) Decreases from the outer circular curves to its center
b) Increases from the outer circular curves to its center
c) Remains constant

Q3. In a weather map, the cold front is depicted with a curve:
a) Blue with small triangles
b) Red with small semicircular shapes
c) Pink with small triangles and semicircular

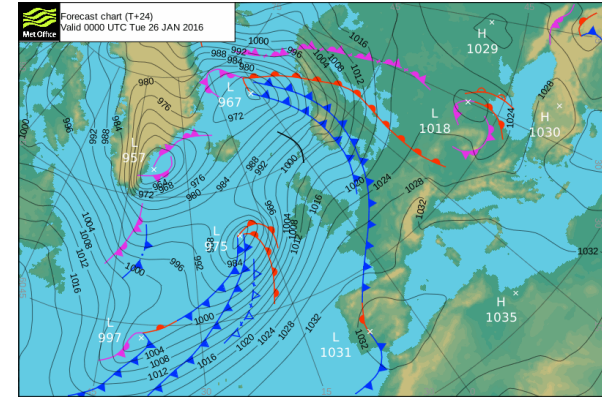

shapes

Q4. More severe weather conditions, such as storms, hail and heavy rainfall, are often associated with the passage of one:
a) Warm front
b) Stationary front
c) Cold front

Q5. At the passage of a front, it is forced to raise the:
a) Colder and denser air mass
b) Warmer and less dense air mass
c) Faster moving air mass

Q6. An air mass is considered unstable when there is cool and dry air near the surface and hot and humid air high:
a) True
b) False

Q7. The energy required for the movement of the hydrological cycle comes from:
a) The wind
b) The oceans
c) The sun

Q8. What are the three stages of the hydrological cycle?
a) Evaporation, condensation, precipitation
b) Condensation, precipitation, perspiration
c) Precipitation, sublimation, evaporation

Q9. The clouds that appear in the image below and have vertical growth while often showing a flat base are called:
a) Cirrus
b) Cumulus
c) Stratus

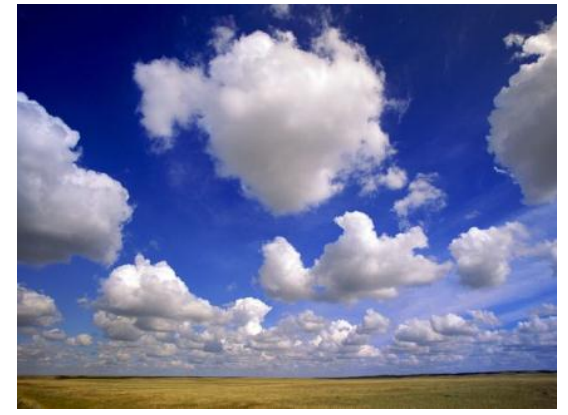


Q10. Thunderstorms are associated to the following types of clouds:

a) Altocumulus

b) Cumulonimbus

c) Cirrocumulus

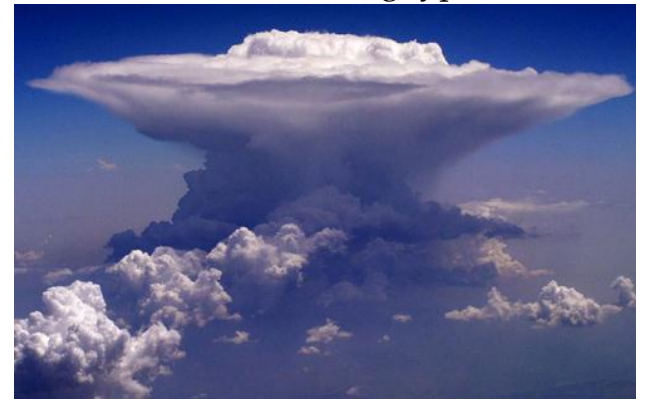

Q11. Higher winds and heavier rainfall occur in the eye of the cyclone:
a) True
b) False

Q12. Which of the following is not a feature of lightning?
a) Lightning is a form of alternating current.
b) Lightning is the result of the separation of the charge in the clouds
c) The visible flash of lightning usually travels from the cloud to the ground

Q13. Which of the following occurs in all thunderstorms?
a) Lightning
b) The tornado
c) The hail

Q14. What are the 3 necessary conditions for the occurrence of a thunderstorm?
a) Humidity, Unstable air mass, Elevating force
b) Humidity, Stable air mass, Heat
c) Lifting force, Front, Humidity

Q15. The cloud in the image below represents, during a thunderstorm, the stage of:
a) Development
b) Maturation
c) Dissipation

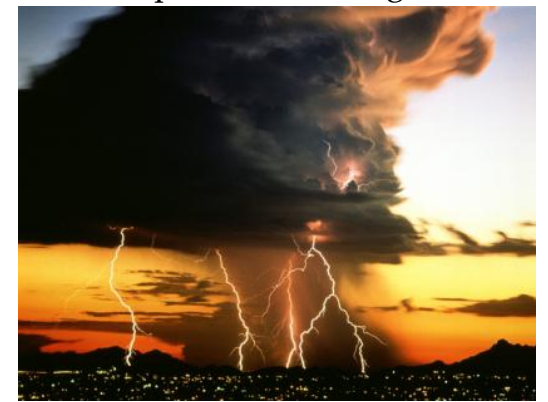

Q16. What are the appropriate temperature conditions to create a strong thunderstorm?
a) High temperatures in the soil and low in the upper layers
b) Low temperatures in the soil and higher in the upper layers
c) High temperatures in the soil and in the upper layers

Q17. The necessary condition for the creation of a tornado during the evolution of a thunderstorm is:
a) Low temperature
b) A change in wind direction and speed at high altitudes
c) Hail

Q18. The role of condensing nuclei in the atmosphere can play:
a) Salt
b) The leaves of the trees
c) Air molecules

Q19. The electric charge in clouds is due to:

a) The collision of ice crystals

b) The strong winds 
c) The presence of a tornado

Q20. In the dissipation stage of a thunderstorm, we have:

a) Only upward current

b) Ascending and descending current

c) Descending current only 


\section{Annex B: Questionnaire for teachers.}

I. Were the learning objectives of the program clear?

II. Is the cognitive content presented related to the educational school program?

III. How satisfactory are the organization and the structure of the learning program?

IV. In the implementation of the learning program, do the students get familiar with the meteorological phenomena?

V. Is the group collaboration of the students ensured during the implementation of the program?

VI. Are the terms and concepts of Meteorology clearly approached?

VII. Suggestions for improvement: if you wish, give a short suggestion.

VIII. Do the presenters manage to arouse interest in the subject of the program?

IX. Are the presenters generally friendly to the students?

X. Evaluate your communication with the presenters

XI. Overall, what do you think of the presenters?

XII. Did you participate in the program to support a specific course? If so, for which course?

XIII. What is the specialty of the accompanying teachers?

XIV. Which class in your school attended the program?

$\mathrm{XV}$. Would you recommend the program to other schools? 